\title{
The effect of photobiomodulation on root resorption during orthodontic treatment
}

This article was published in the following Dove Press journal:

Clinical, Cosmetic and Investigational Dentistry

15 January 2014

Number of times this article has been viewed

\section{Ghada Nimeri \\ Chung $\mathrm{H} \mathrm{Kau}$ \\ Rachel Corona \\ Jeffery Shelly}

Department of Orthodontics, University of Alabama, Birmingham, AL, USA
Correspondence: Professor Chung H Kau Department of Orthodontics, University of Alabama, School of Dentistry Building 305, Box 57, I530 3rd Ave S, Birmingham,

AL 35294-0007, USA

Tel +l 2059342782

Fax +l 2059757590

Email ckau@uab.edu
Abstract: Photobiomodulation is used to accelerate tooth movement during orthodontic treatments. The changes in root morphology in a group of orthodontic patients who received photobiomodulation were evaluated using the cone beam computed tomography technique. The device used is called OrthoPulse, which produces low levels of light with a near infrared wavelength of $850 \mathrm{~nm}$ and an intensity of $60 \mathrm{~mW} / \mathrm{cm}^{2}$ continuous wave. Twenty orthodontic patients were recruited for these experiments, all with class 1 malocclusion and with Little's Irregularity Index $(>2 \mathrm{~mm})$ in either of the arches. Root resorption was detected by measuring changes in tooth length using cone beam computed tomography. These changes were measured before the orthodontic treatment and use of low-level laser therapy and after finishing the alignment level. Little's Irregularity Index for all the patients was calculated in both the maxilla and mandible and patients were divided into three groups for further analysis, which were then compared to the root resorption measurements. Our results showed that photobiomodulation did not cause root resorption greater than the normal range that is commonly detected in orthodontic treatments. Furthermore, no correlation between Little's Irregularity Index and root resorption was detected.

Keywords: photobiomodulation, root resorption, accelerate tooth movement, orthodontics, cone beam computed tomography

\section{Introduction}

Innovations in orthodontics have occurred in the last decade through the continuous modification of wires and brackets. These improvements have not necessarily translated to shorter treatment, and most patients still have to go through a period of fixed orthodontic appliance treatment that lasts between 2 and 3 years. Advancements in therapeutic technologies have created new avenues, which clinicians may potentially use to reduce treatment time.

Every clinician is confronted with the challenging question of how to reduce the duration of orthodontic treatment. Treatment duration is one of the drawbacks of facial orthodontic treatment, and the longer the patient is in treatment, the higher the risks and side effects, which include compliance with treatment, risk of caries, gingival inflammation, and root resorption. A number of attempts have been made, however, both preclinically and clinically, to try to achieve quicker results. These attempts can be categorized into traditional orthodontic biomechanics (frictionless orthodontic systems), pharmacological, surgical, and device-assisted therapeutic (DAT) approaches.

It is not within the scope of this article to describe in detail all the various approaches; only DAT will be described herein. A number of different DAT techniques 
have been used in an attempt to accelerate tooth movement. These techniques are pulsed electromagnetic field, cyclical forces, static magnetic field, resonance vibration, and, finally low-level laser therapy. Low-level laser therapy is a medical and veterinary treatment that uses low-level lasers or lightemitting diodes to alter cellular function. Low-level laser therapy is controversial in mainstream medicine; research to determine whether there is a demonstrable effect is ongoing. Some authors have also described light therapy as photobiomodulation. ${ }^{1}$

Low-level laser therapy is a widely investigated technique. In short, the laser has a biostimulatory effect on bone regeneration, which has been seen in the midpalatal suture during rapid palatal expansion. ${ }^{2}$ It also stimulates bone regeneration after bone fractures and in extraction sites. ${ }^{3,4}$ Some have found that it can accelerate tooth movement in rats, ${ }^{5}$ and clinical trials were undertaken in which different intensities of laser were used and different results were obtained, ${ }^{6-8}$ as discussed later. Low-level laser therapy can be a good technique for acceleration of tooth movement because it increases bone remodeling without side effects in the periodontium. In addition, low-level laser therapy has shown increased rates of ATP (adenosine-triphosphate) production.

When teeth move very quickly during orthodontic treatment, there is a natural tendency to worry about change to root morphology and the reason for these accelerated changes are that the changes are not physiological. All orthodontic treatment will result in some kind of root resorption - it is an unavoidable side effect associated with orthodontic treatment. The severity of root resorption is unpredictable and depends on multiple factors, such as individual biological variables, genetics, and mechanical factors. ${ }^{9,10}$ These multiple factors might be related to root morphology, abnormalities, endodontic treatments, severity of malocclusion, and trauma. Examples of systemic and genetic factors are hormone deficiency, hypothyroidism, and hypopituitarism, as discussed by Weltman et al in 2010. The mechanical factors are those related to the orthodontic treatments, such as direction and magnitude of the applied force, treatment techniques, and type of appliances used. ${ }^{11-13}$ It has also been shown that treatment variables show different results; for example, overjet treatments show more resorption than overbite treatments. ${ }^{14}$ It has been shown that root resorption can range from $1.4 \mathrm{~mm}$ to more than $2 \mathrm{~mm}$ in maxillary incisors; however, adults showed more resorption than children in the mandibular segment only. ${ }^{14}$

Previously, periapical and panoramic radiographs have been the most used techniques for detection of root resorption. It has been shown that the resorption in the majority of teeth is less than $2.5 \mathrm{~mm}$ and differs in the range of $10 \%$ for different teeth. ${ }^{15-18}$ Severe root resorption is classified by the Malmgren index as more than $4 \mathrm{~mm}$ and $1 \%-5 \%$ of the root length. ${ }^{19}$

Periapical radiographs are one of the most used techniques in measuring tooth length and estimating root resorption; however, with this technique, errors can occur due to angulation error, linear error, and film bending. Furthermore, with two-dimensional radiographs, occurrence of overlapping makes it difficult to identify some anatomic points, ${ }^{20}$ which is why using cone beam computed tomography (CBCT) systems can be considered to be more reliable.

Three-dimensional CBCT provides valuable information regarding bone thickness and morphology for the positioning of titanium implants, an important tool for surgical planning and detecting the location of an impacted tooth, asymmetries, and airway construction, and for measuring root resorption. In a study by Sherrard et al, in which CBCT scans were made of seven fresh porcine heads and then compared with the actual tooth length after all the surrounding bone had been carefully removed, tooth length and root length measured by $\mathrm{CBCT}$ were not significantly different from the actual tooth length. ${ }^{21}$ The study also showed that the method error in evaluating root length was two times greater for periapical radiographs versus CBCT method. ${ }^{21}$

The aim of the present study was to evaluate changes in root morphology in a group of orthodontic patients who had received photobiomodulation using the cone beam computed tomography technique.

\section{Materials and methods Patient recruitment}

Twenty subjects were recruited to participate in a study to accelerate tooth movement using low-level laser therapy. Their ages ranged from 11-32 years. Patients requiring orthodontic treatment who met the following inclusion criteria were invited to participate in the study: 1) permanent dentition; 2) expected by the investigator to be compliant with device use; 3) class I malocclusion with irregularity score of $>2 \mathrm{~mm}$ in either one of the dental arches; and 3) good oral hygiene, as determined by the investigating orthodontist. The exclusion criteria for the study were as follows: 1) any medical or dental condition that, in the opinion of the investigator, could negatively affect study results during the expected length of the study; 2) currently using any investigational drug or any other investigational device; 3) planning to relocate or move during the treatment period; 4) allergic to acetaminophen (use of aspirin or nonsteroidal anti-inflammatory 
drugs is excluded for patients while on the study); 5) use of bisphosphonates (osteoporosis drugs) during the study; and 6) pregnancy.

\section{OrthoPulse device}

The OrthoPulse uses photobiomodulation, a form of lowlevel light therapy, and is manufactured by Biolux Research Ltd (Vancouver, BC, Canada). The device is intended to provide stimulation for accelerating orthodontic movement of teeth according to the principles of photobiomodulation. The OrthoPulse produces low levels of light with a near infrared wavelength of $850 \mathrm{~nm}$ and an intensity of less than $100 \mathrm{~mW} / \mathrm{cm}^{2}$ continuous wave. Industry-standard lightemitting diodes (LEDs) are used to produce the light, with arrays of emitters arranged on a series of treatment arrays to cover the target area of the alveolus of both the maxilla and mandible.

The OrthoPulse consists of three main components:

1. A small, handheld controller that houses the microprocessor, the menu-driven software, and the liquid crystal display (LCD) screen. The controller is programmable by the investigator for the number of treatment sessions and the session duration. The user interface indicates to the patient the number of sessions completed and the remaining time in each session. The controller plugs into the power mains via a medically approved, certified power supply.

2. A set of four extra-oral treatment arrays, each with a flexible printed circuit board and a set of LEDs mounted to a contoured heatsink and infrared-transmissible plastic lens, with conductive cables to the controller.

3. A headset similar to an eyeglass-support structure, to be worn by the patient on a daily or weekly basis, with attachment and adjustment mechanisms for positioning the treatment arrays in the appropriate location for the given patient.

\section{CBCT imaging device}

The Kodak 9500 CBCT (Carestream Dental LLC, Atlanta, Georgia, USA) machine was used. This device was used for hard tissue acquisition, and a series of two dimensional projections was obtained. Data from the projections were reconstructed using sophisticated algorithms, and the process resulted in the axial, coronal, and sagittal plane x-ray projections of the patient's skull. The device allows radiation dose control through variable $\mathrm{mA}$ and $\mathrm{kV}$ settings. The CBCT scan of the patient was taken with a field of view of $18 \times 25 \mathrm{~cm}$ and a voxel resolution of $0.3 \mathrm{~mm}$. Each of the 599 slices was saved in a Dicom file format.

\section{Measuring root resorption by CBCT}

Two CBCT scans were taken (one at each time point) before orthodontic treatment (T1) and at the completion of the alignment or space closure phase of treatment (T2). The teeth that were investigated were from the first molar of the right side to the first molar of the left side in both arches. Either the first premolar or the second premolar was extracted during the treatment and excluded from the measurements.

Root morphologies were calculated by measuring the whole length of the tooth before orthodontic treatment minus the whole length after the end of the alignment level (T1 T2). The whole length of each tooth was measured from the highest point at the crown to the highest point at the apex of the root (Figure 1). The difference between T1 and T2 represented a change in root morphology and was assumed to be root resorption.

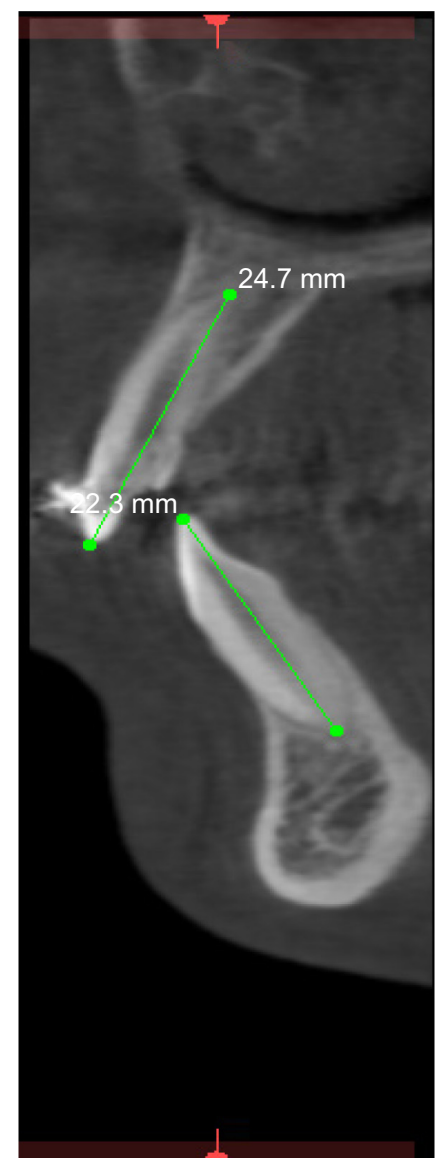

Figure I Measuring the changes in root length by cone beam computed tomography.

Notes: Tooth length measurements were carried out by using a cone beam computed tomography radiograph. The measurements were taken from the highest incisal edge of the tooth to the highest point of the apex. As shown here, the upper-left central incisor is about $24.7 \mathrm{~mm}$, and the lower left central is $22.3 \mathrm{~mm}$. 


\section{Orthodontic mechanics}

\section{used and duration}

Traditional orthodontic brackets and wires were used for all subjects participating in the study. The wire sequences for each of these sites were standardized to an initial round alignment wire $(014 \mathrm{Niti}, 16 \times 22 \mathrm{Niti})$ and final rectangular alignment wire of at least $18 \times 25$ stainless steel. The following parameters were included in the analysis: 1) root morphology; 2) difference in root length before and after treatment; 3) correlation of Little's Irregularity Index (LII) with root resorption and alignment rate; and 4) root differences with cutoffs between 0.40 to $0.60 \mathrm{~mm}$.

\section{LII and alignment rate measurements}

LII was used to measure distances between the anatomical contact points between the anterior six teeth on the maxilla and mandible in the horizontal occlusal plane. The sum of these points for each patient for the maxilla and mandible was considered to be crowding. LII was measured before the orthodontic treatment, then at the different intervals during the orthodontic treatment, and, finally, at the end of the treatment. The alignment rate for the maxilla and mandible for each patient was calculated by dividing the LII before treatment by the number of weeks it took to reach $\mathrm{LII}=0$.

\section{Statistics}

Stata software (v 12; StataCorp LP, College Station, TX, USA) was used to conduct the analyses in this study, and paired $t$-test was used for the mean of root resorption measurements. The Wilcoxon rank-sum or Mann-Whitney test were used for LII and alignment measurement. $P<0.05$ indicated statistical significance.

\section{Results}

\section{Subjects}

Twenty subjects were recruited for this study, comprising 15 females and five males, of whom 13 were aged between 11 and 15 years and seven between 22 and 36 years.

\section{Root morphology measurements at T2 compared to TI}

The changes in root morphology for the 20 patients were analyzed. The mean length of tooth was measured first before treatment as $\mathrm{T} 1$ and at the end of alignment and levelling process as T2. The mean changes in root morphology were calculated as $\mathrm{T} 1-\mathrm{T} 2$ for teeth in the maxilla and
Table I Root resorption measurements of upper teeth at T2 compared to TI

\begin{tabular}{lllll}
\hline Upper teeth & $\begin{array}{l}\text { Mean TI } \\
(\mathbf{m m})\end{array}$ & $\begin{array}{l}\text { Mean T2 } \\
(\mathbf{m m})\end{array}$ & $\begin{array}{l}\text { Mean TI - T2 } \\
(\mathbf{m m})\end{array}$ & $\begin{array}{l}\text { Standard } \\
\text { deviation }\end{array}$ \\
\hline Right Ist palatal & 19.62 & 19.16 & 0.46 & 0.97 \\
molar & & & & \\
Mesiobuccal root & 18.62 & 18.20 & 0.42 & 0.94 \\
Distobuccal root & 17.02 & 16.87 & 0.15 & 0.64 \\
Right 2nd buccal & 20.35 & 20.1 & 0.25 & 0.87 \\
premolar & & & & \\
Palatal root & 20.08 & 20.70 & -0.62 & 1.75 \\
Right Ist buccal & 20.09 & 19.86 & 0.23 & 1.66 \\
premolar & & & & \\
Palatal & 19.07 & 19.70 & -0.63 & 2.87 \\
Right canine root & 26.69 & 24.66 & -2.03 & 0.99 \\
Right lateral root & 22.20 & 21.50 & 0.70 & 1.25 \\
Right central root & 22.74 & 22.01 & 0.74 & 1.26 \\
Left central root & 23.12 & 22.74 & 0.38 & 0.97 \\
Left lateral root & 22.70 & 21.95 & 0.75 & 1.30 \\
Left canine & 24.85 & 25.71 & -0.75 & 1.25 \\
Left Ist buccal & 19.84 & 19.85 & -0.01 & 1.16 \\
premolar & & & & \\
Palatal & 19.81 & 19.20 & 0.60 & 2.40 \\
Left 2nd buccal & 21.04 & 20.85 & 0.19 & 0.68 \\
premolar & & & & 0.50 \\
Palatal & 20.82 & 20.87 & -0.05 & 0.90 \\
Left Ist palatal & 19.61 & 19.38 & 0.23 & 1.26 \\
\hline $\begin{array}{l}\text { molar } \\
\text { Mesiobuccal }\end{array}$ & 18.70 & 18.09 & 0.61 & \\
Distobuccal & 17.27 & 16.96 & 0.30 & \\
\hline Notes: Mean toot & & & \\
\hline
\end{tabular}

Notes: Mean tooth length was measured first before the orthodontic treatment (TI) then at the end of the alignment and levelling process (T2). The mean root resorption was calculated as $\mathrm{TI}-\mathrm{T} 2$ for teeth in the maxilla.

Table 2 Root resorption measurements of lower teeth at T2 compared to TI

\begin{tabular}{lllll}
\hline Lower teeth & $\begin{array}{l}\text { Mean } \\
\text { TI } \\
(\mathbf{m m})\end{array}$ & $\begin{array}{l}\text { Mean } \\
\text { T2 } \\
(\mathbf{m m})\end{array}$ & $\begin{array}{l}\text { Mean } \\
\text { TI }-\mathbf{T 2} \\
(\mathbf{m m})\end{array}$ & $\begin{array}{l}\text { Standard } \\
\text { deviation }\end{array}$ \\
\hline Right Ist distal molar & 20.46 & 20.01 & 0.45 & 0.87 \\
Right Ist mesial molar & $19.5 \mathrm{I}$ & 18.76 & 0.75 & 1.28 \\
Right 2nd premolar & 21.52 & 21.13 & 0.39 & 0.93 \\
Right Ist premolar & 21.08 & 20.20 & 0.88 & 0.87 \\
Right canine & 25.73 & $25.4 \mathrm{I}$ & 0.32 & 0.70 \\
Right lateral & 22.68 & $21.9 \mathrm{I}$ & 0.77 & 1.40 \\
Right central & 21.38 & $20.7 \mathrm{I}$ & 0.67 & 1.24 \\
Left central & 21.37 & 20.18 & 1.19 & 1.32 \\
Left lateral & 22.45 & 21.28 & 1.17 & 0.77 \\
Left canine & 25.26 & 24.49 & 0.77 & 0.92 \\
Left Ist premolar & 20.6 & 19.94 & 0.66 & $0.5 \mathrm{I}$ \\
Left 2nd premolar & 20.79 & 20.36 & 0.43 & 0.95 \\
Left Ist distal molar & 20.82 & 19.97 & 0.85 & 0.85 \\
Left Ist mesial molar & 19.93 & 19.17 & 0.76 & 1.23 \\
\hline Notes: Mean
\end{tabular}

Notes: Mean tooth length was measured first before the orthodontic treatment (TI) then at the end of the alignment and levelling process (T2). The mean root resorption was calculated as $\mathrm{TI}-\mathrm{T} 2$ for teeth in the mandible. 
the mandible (Tables 1 and 2). The mean values for tooth length in the maxilla before the treatment (T1) ranged from $17.02-26.69 \mathrm{~mm}$ and the mean values for tooth length in the maxilla after treatment (T2) ranged from 16.87-25.71 mm (Table 1). The mean values for tooth length in the mandible before treatment (T1) ranged from 19.51-25.73 $\mathrm{mm}$ and the mean values for tooth length in the mandible after treatment (T2) ranged from 19.17-25.41 mm (Table 2).

The mean root resorption for all the maxillary roots (T1 - T2) ranged from $0.15-0.75 \mathrm{~mm}$ (Table 1). There was, however, an increase in the length (elongation) ranging from -0.01 to $-2.03 \mathrm{~mm}$ in the first and second premolars and upper canines (Table 1). In addition, the mean root resorption for the mandibular roots $(\mathrm{T} 1-\mathrm{T} 2)$ ranged from 0.32-1.19 mm (Table 2).

\section{Correlation between LII and root resorption}

LII was calculated for both maxilla and mandible for all the patients; for the maxilla, this ranged from 1-20.61 mm and, for the mandible, 1-16.61 $\mathrm{mm}$, which illustrates the degree of crowding (Table 3 ). The alignment rate for the maxilla ranged from $0.05-2.48 \mathrm{~mm} /$ week and, for the mandible, $0.12-2.26 \mathrm{~mm} / \mathrm{w}$ (Table 3 ). The mean alignment rate for the maxilla was calculated and was $1.03 \mathrm{~mm} / \mathrm{w}$, and, for the mandible, $0.92 \mathrm{~mm} / \mathrm{w}$.
The mean LII values for all the patients were divided into three groups: group 1, LII $<6 \mathrm{~mm}$; group 2, LII 6-10 mm; and group 3, LII $>10 \mathrm{~mm}$. The mean resorptions for each of the three LII groups were compared. No significant differences were found between the mean value of the root resorption in each of the three LII groups; in other words, there was no correlation detected between LII and root resorption (Table 4).

\section{Analysis of the level of root resorption at $0.40-0.60 \mathrm{~mm}$}

Statistical analysis of the level of root resorption at $0.40-0.60 \mathrm{~mm}$ was performed. A statistically significant amount of root resorption was found at the level between 0.40 and $0.50 \mathrm{~mm}$, and nonsignificance was found at values above $0.50 \mathrm{~mm}$ (Table 5). These results indicate that the changes in the root lengths at the end of the treatment were not statistically significant at values higher than $0.50 \mathrm{~mm}$ and these values were considered to be within the clinically acceptable limits.

\section{Discussion}

Previously, studies of animal experiments showed that the laser wavelength of $800 \mathrm{~nm}$ and output power of $0.25 \mathrm{~mW}$ indicated significant stimulation of bone metabolism and rapid ossification. ${ }^{4,5}$ It has also been shown that low-level laser therapy accelerated tooth movement 1.5 -fold in rat experiments. $^{22}$ In a recent clinical trial study by Doshi-Mehta and

Table 3 Alignment rate and Little's Irregularity Index (LII) in maxilla and mandible for each patient

\begin{tabular}{lllll}
\hline Patient code & LII maxilla $(\mathbf{m m})$ & $\begin{array}{l}\text { Alignment rate } \\
\text { maxilla }(\mathbf{m m} / \mathbf{w})\end{array}$ & LII mandible $(\mathbf{m m})$ & $\begin{array}{l}\text { Alignment rate mandible } \\
(\mathbf{m m} / \mathbf{w})\end{array}$ \\
\hline 01 & 10.16 & 0.68 & 10.25 & 0.68 \\
04 & 7.71 & 1.28 & 7.11 & 1.18 \\
06 & 11.72 & 1.06 & 3.43 & 0.31 \\
07 & 9.93 & 2.48 & 6.4 & 1.60 \\
08 & 7.33 & 0.56 & 4.84 & 0.37 \\
09 & 20.61 & 0.79 & 8.95 & 0.34 \\
12 & 8.08 & 1.34 & 0 & 0 \\
13 & 3.35 & 1.67 & 2.5 & 1.25 \\
16 & 0 & 0 & 1 & 0.12 \\
17 & 12.24 & 2.04 & 13.61 & 2.26 \\
18 & 8.93 & 0.44 & 4.86 & 0.24 \\
21 & 4.91 & 0.54 & 13.42 & 1.49 \\
22 & 9.63 & 0.74 & 16.61 & 1.27 \\
23 & 0 & 0 & 2.94 & 1.47 \\
24 & 15.34 & 0.90 & 12.12 & 0.71 \\
27 & 8.81 & 1.46 & 7.61 & 1.26 \\
28 & 8.9 & 0.36 & 9.25 & 0.66 \\
31 & 7.1 & 0.50 & 8.82 & 0.63 \\
32 & 6.23 & 0.69 & 8.76 & 0.97 \\
35 & 1 & 0.05 & 12.15 & 0.71 \\
\hline
\end{tabular}

Note: The mean alignment rate for the maxilla and for the mandible was calculated by dividing the LII rate by the number of weeks to reach LII $=0$. 
Table 4 Correlation between Little's Irregularity Index (LII) and root resorption

\begin{tabular}{llll}
\hline LII comparison & Mean root resorption (A) & Mean root resorption (B) & $\begin{array}{l}\text { Differences in root resorption } \\
\text { between the three LII groups (A - B) }\end{array}$ \\
\hline Groups I and 2 & $\begin{array}{l}\text { LII }<6 \mathrm{~mm} \text { : } \\
\text { mean root resorption }=0.61 \mathrm{~mm}\end{array}$ & $\begin{array}{l}\text { LII }>6 \text { to }<10 \mathrm{~mm}: \\
\text { mean root resorption }=0.57 \mathrm{~mm}\end{array}$ & $0.04 \mathrm{~mm}$ \\
Groups I and 3 & $\begin{array}{l}\text { LII }<6 \mathrm{~mm}: \\
\text { mean root resorption }=0.61 \mathrm{~mm}\end{array}$ & $\begin{array}{l}\text { For LII }>10 \mathrm{~mm}: \\
\text { mean root resorption }=0.63 \mathrm{~mm}\end{array}$ & $-0.02 \mathrm{~mm}$ \\
Groups 2 and 3 & $\begin{array}{l}\text { For LII }>6 \text { to }<10 \mathrm{~mm}: \\
\text { mean root resorption }=0.57 \mathrm{~mm}\end{array}$ & $\begin{array}{l}\text { For LII }>10 \mathrm{~mm}: \\
\text { mean root resorption }=0.63 \mathrm{~mm}\end{array}$ & $-0.06 \mathrm{~mm}$ \\
\hline
\end{tabular}

Notes: The mean values for LII for all patients were divided into three groups: group I, LII $<6$ mm; group 2, LII 6-10 mm; group 3, LII > 10 mm. The mean resorptions for each of the three LIl groups were compared by subtracting one group from the other (A - B). $P$-value $<0.05$.

Bhad-Patil in 2012, tooth movement acceleration 1.3-fold higher was detected. The authors used a laser wavelength of $800 \mathrm{~nm}$, a continuous wave mode, an output of $0.25 \mathrm{~mW}$, and exposure of 10 seconds. In our study, we also detected acceleration in the alignment level, using a wavelength of $850 \mathrm{~nm}$ and intensity of less than $100 \mathrm{~mW} / \mathrm{cm}^{2}$ continuous wave. The mean rate of alignment for maxilla was $1.03 \mathrm{~mm} / \mathrm{w}$ and for mandibles the rate was $0.92 \mathrm{~mm} / \mathrm{w}$. This alignment rate is higher than the rate obtained by others, ${ }^{23,24}$ and also higher than previous results obtained by Kau with the use of cyclic force-generating therapy. ${ }^{25}$

There have been some contradictory results related to low-level laser therapy in the literature, where no effect of acceleration was detected, as shown by Limpanichkul et al in $2006 .{ }^{6}$ The reason for that might have been due to the different energy density used in the experiment, hence why it is very important to use the right optimum wavelength and intensity of laser in tooth movement experiments. The mechanism of acceleration of tooth movement by low-level laser therapy has been investigated previously and is found to be related to the activation of mitochondrial respiratory chain components that promote cellular proliferation by the activation of cytochrome $\mathrm{c}$ oxidase and the production of

Table 5 Significance of root resorption at $0.4-0.6 \mathrm{~mm}$

\begin{tabular}{lll}
\hline Root resorption $\mathbf{( m m})$ & $P$-value & Significance \\
\hline 0.40 & 0.000 & $\mathrm{~S}$ \\
0.42 & 0.000 & $\mathrm{~S}$ \\
0.44 & 0.001 & $\mathrm{~S}$ \\
0.46 & 0.003 & $\mathrm{~S}$ \\
0.48 & 0.011 & $\mathrm{~S}$ \\
0.50 & 0.033 & $\mathrm{~S}$ \\
0.52 & 0.086 & $\mathrm{NS}$ \\
0.54 & 0.194 & $\mathrm{NS}$ \\
0.56 & 0.379 & $\mathrm{NS}$ \\
0.58 & 0.646 & $\mathrm{NS}$ \\
\hline
\end{tabular}

Note: Statistical analysis of the level of root resorption at $0.40 \mathrm{~mm}$ to $0.60 \mathrm{~mm}$ was performed. Statistical significance was at $P<0.05$. Abbreviations: NS, not significant; $S$, significant.
ATP. ${ }^{26,27}$ It has also been shown that low-level laser therapy accelerates tooth movement via RANK/RANKL expression, which was detected in rat experiments at an early stage (days 2 and 3) in the laser-irradiated group. ${ }^{22}$

In this study, we focused on the evaluation of the morphological changes of roots after the use of photobiomodulation by CBCT. In our experiments, the mean root resorption was measured by the subtraction of tooth length after orthodontic and low-level laser therapy from the tooth length before treatment. The changes in root length in the maxillary roots ranged between 0.15 and $0.75 \mathrm{~mm}$ and, for the mandibular roots, between 0.32 and $1.19 \mathrm{~mm}$ (Tables 1 and 2). In the maxilla and mandible, the most resorbed teeth were the lateral followed by the central incisor. These results correlate with the results shown by Sameshima and Sinclair in $2001,{ }^{28}$ who analyzed records obtained from six private offices of 868 patients treated with full, fixededgewise appliances.

It has also been shown in the literature that the majority of root resorption associated with orthodontic treatment is minor, averaging between 0.4 and $1.5 \mathrm{~mm} \cdot{ }^{18,29,30}$ The risk of root resorption is due to multiple factors, such as genetics, tooth root shape, mechanics applied, and duration of treatment. Laterals and centrals are the most affected teeth, but the reason for this is not known. One possible explanation is that laterals are known to have the most abnormal root shapes. It has been shown that an erupting canine can resorb the lateral incisor from the palatal side without being detected by conventional radiographs. ${ }^{31}$

In this study, we detected root elongation in the maxillary premolars and canines. This finding can be due either to a real increase in root length, as shown by others, ${ }^{18,32}$ or an error during measurement. ${ }^{33,34}$ The latter possibility can be excluded since we used CBCT images, which showed more accurate results compared to the periapical and panoramic radiographs. It has been shown that periapical radiographs have led to underestimation of the loss of root 
resorption, while panoramic radiographs have shown $20 \%$ overestimation. ${ }^{35}$

We believe, regarding the first possibility, that root elongation is a real increase in root length. Elongation of teeth after orthodontic treatment was not surprising, since the majority of our patients (about 70\%) were aged 11-14 years and had immature teeth with open apical roots. It has been shown that roots that were incompletely developed before treatment reached a significantly greater length than those that were fully developed at the beginning of the treatment. It has also been suggested that incomplete root formation means a higher resistance to root resorption in posterior teeth. ${ }^{36}$ Orthodontic treatment should be undertaken in younger ages due to the advantage of immature teeth. ${ }^{16}$

LII is a method by which to measure anterior arch crowding. It is the summation of the distances of the tooth contact points along the occlusal axis. Rotation irregularities and displacement can be reflected by the inter-contact positions. The greater the Little's Index, the more anterior crowding is detected and the longer it takes for the completion of the treatment.

We used LII measurements to calculate the alignment rate in maxilla and mandibles for each patient after low-level laser treatments. The alignment rate for the maxilla ranged between 0.05 and $2.48 \mathrm{~mm} / \mathrm{w}$ and mandible rates ranged between 0.12 and $2.26 \mathrm{~mm} / \mathrm{w}$ (Table 3 ). The mean alignment rate for the maxilla was $1.03 \mathrm{~mm} / \mathrm{w}$ and, for the mandible, $0.92 \mathrm{~mm} / \mathrm{w}$. These alignment rates are much higher than those previously published. Wahab et al undertook a study in which conventional ligating brackets (CLB) and self-ligating brackets (SLB) were compared for 120 days in extraction cases. ${ }^{23}$ The alignment rate calculated for the maxilla using CLB was $0.73 \mathrm{~mm} / \mathrm{w}$ and, using SLB, $0.50 \mathrm{~mm} / \mathrm{w}$. A similar experiment has been performed, and the alignment rate calculated in 20 weeks was $0.41 \mathrm{~mm} / \mathrm{w}$ by CLB and $0.38 \mathrm{~mm} / \mathrm{w}$ by SLB. ${ }^{37}$ Non-extraction cases have shown similar results, and the alignment rate ranged between 0.44 and $0.52 \mathrm{~mm} / \mathrm{w}$, as shown by Miles and Weyant ${ }^{38}$ and Pandis et al in $2010 .^{24}$ Thus, photobiomodulation showed a higher alignment rate and accelerated tooth movement than others.

For the comparison of LII groups and root resorption we calculated the LII on the cast models for all the patients and divided them into the three groups described previously. The mean root resorption for each group was calculated and compared to the others. There was no correlation between LII and root resorption (Table 4). This shows that root resorption was not affected by the amount of crowding nor by how much teeth were moved, since teeth with
LII $>10 \mathrm{~mm}$ showed similar root resorption as teeth with a lower LII.

Significance of root resorption was found at the range of $0.40-0.50 \mathrm{~mm}$ (Table 5). This value is in the range of normal root resorption, as shown in the literature. ${ }^{13}$ In our experiments, we found that $70 \%$ of our patients had root resorption $(>0-1 \mathrm{~mm})$, and these results are comparable to those obtained by Lund et al in 2012. ${ }^{29}$

The main limitation of this study was the lack of a control group; however, our results are comparable to those found in the literature. ${ }^{1}$

\section{Conclusion}

The Orthopulse photobiomodulation device can be used clinically for acceleration of tooth movement. Low-level laser therapy did not cause more root resorption than the normal range that is commonly detected by orthodontic treatments. There was no correlation between LII and root resorption. No clinically significant changes between root lengths were detected above $0.5 \mathrm{~mm}$.

\section{Disclosure}

Dr Kau is principal investigator on a clinical trial sponsored by Biolux Research Limited. The other authors have no conflicts of interest to disclose.

\section{References}

1. Kau CH, Kantarci A, Shaughnessy T, Vachiramon A, Santiwog P, de la Fuente A, et al. Photobiomodulation accelerates orthodontic alignment in the early phase of treatment. Prog Orthod. 2013;14:30.

2. Saito S, Shimizu N. Stimulatory effects of low-power laser irradiation on bone regeneration in midpalatal suture during expansion in the rat. Am J Orthod Dentofacial Orthop. 1997;111:525-532.

3. Trelles MA, Mayayo E. Bone fracture consolidates faster with low-power laser. Lasers Surg Med. 1987;7:36-45.

4. Takeda Y. Irradiation effect of low-energy laser on alveolar bone after tooth extraction. Experimental study in rats. Int J Oral Maxillofac Surg. 1988; 17:388-391.

5. Kawasaki K, Shimizu N. Effects of low-energy laser irradiation on bone remodeling during experimental tooth movement in rats. Lasers Surg Med. 2000;26:282-291.

6. Limpanichkul W, Godfrey K, Srisuk N, Rattanayatikul C. Effects of low-level laser therapy on the rate of orthodontic tooth movement. Orthod Craniofac Res. 2006;9:38-43.

7. Doshi-Mehta G, Bhad-Patil WA. Efficacy of low-intensity laser therapy in reducing treatment time and orthodontic pain: a clinical investigation. Am J Orthod Dentofacial Orthop. 2012;141:289-297.

8. Youssef M, Ashkar S, Hamade E, Gutknecht N, Lampert F, Mir M. The effect of low-level laser therapy during orthodontic movement: a preliminary study. Lasers Med Sci. 2008;23:27-33.

9. Weltman B, Vig KW, Fields HW, Shanker S, Kaizar EE. Root resorption associated with orthodontic tooth movement: a systematic review. Am J Orthod Dentofacial Orthop. 2010;137:462-476.

10. Linge L, Linge BO. Patient characteristics and treatment variables associated with apical root resorption during orthodontic treatment. Am J Orthod Dentofacial Orthop. 1991;99:35-43. 
11. Weiland F. Constant versus dissipating forces in orthodontics: the effect on initial tooth movement and root resorption. Eur J Orthod. 2003;25:335-342.

12. Harris DA, Jones AS, Darendeliler MA. Physical properties of root cementum: part 8. Volumetric analysis of root resorption craters after application of controlled intrusive light and heavy orthodontic forces: a microcomputed tomography scan study. Am J Orthod Dentofacial Orthop. 2006;130:639-647.

13. Chan E, Darendeliler MA. Physical properties of root cementum: part 7. Extent of root resorption under areas of compression and tension. Am J Orthod Dentofacial Orthop. 2006;129:504-510.

14. Sameshima GT, Sinclair PM. Predicting and preventing root resorption: part I. Diagnostic factors. Am J Orthod Dentofacial Orthop. 2001;119:505-510.

15. Blake M, Woodside DG, Pharoah MJ. A radiographic comparison of apical root resorption after orthodontic treatment with the edgewise and Speed appliances. Am J Orthod Dentofacial Orthop. 1995; 108:76-84.

16. Mavragani M, Bøe OE, Wisth PJ, Selvig KA. Changes in root length during orthodontic treatment: advantages for immature teeth. Eur $J$ Orthod. 2002;24:91-97.

17. Brezniak N, Wasserstein A. Root resorption after orthodontic treatment: part 2. Literature review. Am J Orthod Dentofacial Orthop. 1993;103:138-146.

18. Linge BO, Linge L. Apical root resorption in upper anterior teeth. Eur J Orthod. 1983;5:173-183.

19. Levander E, Malmgren O. Evaluation of the risk of root resorption during orthodontic treatment: a study of upper incisors. Eur J Orthod. 1988;10:30-38.

20. Westphalen VP, Gomes de Moraes I, Westphalen FH, Martins WD, Souza PH. Conventional and digital radiographic methods in the detection of simulated external root resorptions: a comparative study. Dentomaxillofac Radiol. 2004;33:233-235.

21. Sherrard JF, Rossouw PE, Benson BW, Carrillo R, Buschang PH. Accuracy and reliability of tooth and root lengths measured on conebeam computed tomographs. Am J Orthod Dentofacial Orthop. 2010; 137:100-108.

22. Fujita S, Yamaguchi M, Utsunomiya T, Yamamoto H, Kasai K. Low-energy laser stimulates tooth movement velocity via expression of RANK and RANKL. Orthod Craniofac Res. 2008;11: 143-155.

23. Wahab RM, Idris H, Yacob H, Ariffin SH. Comparison of self- and conventional-ligating brackets in the alignment stage. Eur J Orthod. 2012;34:176-181.
24. Pandis N, Polychronopoulou A, Eliades T. Active or passive self-ligating brackets? A randomized controlled trial of comparative efficiency in resolving maxillary anterior crowding in adolescents. Am J Orthod Dentofacial Orthop. 2010;137:12. e1-e6; discussion 12-13.

25. Kau $\mathrm{CH}$. A radiographic analysis of tooth morphology following the use of a novel cyclic force device in orthodontics. Head Face Med. 2011;9:7-14.

26. Karu TI. Mitochondrial signaling in mammalian cells activated by red and near-IR radiation. Photochem Photobiol. 2008;84:1091-1099.

27. Eells JT, Henry MM, Summerfelt P, et al. Therapeutic photobiomodulation for methanol-induced retinal toxicity. Proc Natl Acad Sci U S A. 2003;100:3439-3444.

28. Sameshima GT, Sinclair PM. Predicting and preventing root resorption: part II. Treatment factors. Am J Orthod Dentofacial Orthop. 2001; 119:511-515.

29. Lund H, Gröndahl K, Hansen K, Gröndahl HG. Apical root resorption during orthodontic treatment. A prospective study using cone beam CT. Angle Orthod. 2012;82:480-487.

30. Makedonas D, Lund H, Hansen K. Root resorption diagnosed with cone beam computed tomography after 6 months and at the end of orthodontic treatment with fixed appliances. Angle Orthod. 2013;83(3):389-393.

31. Brin I, Becker A, Zilberman Y. Resorbed lateral incisors adjacent to impacted canines have normal crown size. Am J Orthod Dentofacial Orthop. 1993;104:60-66.

32. Mavragani M, Vergari A, Selliseth NJ, Bøe OE, Wisth PL. A radiographic comparison of apical root resorption after orthodontic treatment with a standard edgewise and a straight-wire edgewise technique. Eur J Orthod. 2000;22:665-674.

33. Mirabella AD, Artun J. Prevalence and severity of apical root resorption of maxillary anterior teeth in adult orthodontic patients. Eur J Orthod. 1995;17:93-99.

34. Baumrind S, Korn EL, Boyd RL. Apical root resorption in orthodontically treated adults. Am J Orthod Dentofacial Orthop. 1996;110:311-320.

35. Sameshima GT, Asgarifar KO. Assessment of root resorption and root shape: periapical vs panoramic films. Angle Orthod. 2001;71: 185-189.

36. Hendrix I, Carels C, Kuijpers-Jagtman AM, Van 'T Hof M. A radiographic study of posterior apical root resorption in orthodontic patients. Am J Orthod Dentofacial Orthop. 1994;105:345-349.

37. Ong E, McCallum H, Griffin MP, Ho C. Efficiency of self-ligating vs conventionally ligated brackets during initial alignment. Am J Orthod Dentofacial Orthop. 2010;138(2):138. e1-e7; discussion 138-139.

38. Miles P, Weyant R. Porcelain brackets during initial alignment: are self-ligating cosmetic brackets more efficient? Aust Orthod J. 2010;26:21-26.
Clinical, Cosmetic and Investigational Dentistry

\section{Publish your work in this journal}

Clinical, Cosmetic and Investigational Dentistry is an international, peer-reviewed, open access, online journal focusing on the latest clinical and experimental research in dentistry with specific emphasis on cosmetic interventions. Innovative developments in dental materials, techniques and devices that improve outcomes and patient satisfac-

\section{Dovepress}

tion and preference will be highlighted. The manuscript management system is completely online and includes a very quick and fair peerreview system, which is all easy to use. Visit http://www.dovepress. com/testimonials.php to read real quotes from published authors. 